\title{
ORIGINAL ARTICLE \\ Mediation of seed provisioning in the transmission of environmental maternal effects in Maritime pine (Pinus pinaster Aiton)
}

\author{
R Zas, C Cendán and L Sampedro
}

Although maternal environmental effects are increasingly recognized as an important source of phenotypic variation with relevant impacts in evolutionary processes, their relevance in long-lived plants such as pine trees is largely unknown. Here, we used a powerful sample size and a strong quantitative genetic approach to analyse the sources of variation of early seedling performance and to identify seed mass (SM)-dependent and -independent maternal environmental effects in Maritime pine. We measured SM of 8924 individual seeds collected from 10 genotypes clonally replicated in two environments of contrasting quality (favourable and stressful), and we measured seedling growth rate and biomass allocation to roots and shoots. SM was extremely variable (up to 14-fold) and strongly determined by the maternal environment and the genotype of the mother tree. The favourable maternal environment led to larger cones, larger seeds and reduced SM variability. The maternal environment also determined the offspring phenotype, with seedlings coming from the favourable environment being 35\% larger and with greater root/shoot ratio. Transgenerational plasticity appears, thus, to be a relevant source of phenotypic variation in the early performance of this pine species. Seed provisioning explained most of the effect of the maternal environment on seedling total biomass. Environmental maternal effects on seedling biomass allocation were, however, determined through SM-independent mechanisms, suggesting that other epigenetic regulation channels may be involved. Heredity (2013) 111, 248-255; doi:10.1038/hdy.2013.44; published online 8 May 2013

Keywords: conifer; seedling performance; seed-mass variability; seed mass; seed weight; transgenerational plasticity

\section{INTRODUCTION}

That mother plants can alter the phenotype of their offspring in response to the environmental conditions where they grow has been reported in several species across a range of environments (reviewed in Herman and Sultan, 2011). Increasing evidence is accumulating that environmental maternal effects may be adaptive, enhancing the fitness of the offspring when established under environmental conditions that resemble the maternal environment (Galloway and Etterson, 2007; Herman and Sultan, 2011). This form of adaptive transgenerational plasticity has been reported in response to several biotic and abiotic environmental cues, including temperature (Yakovlev et al., 2010), drought (Herman et al., 2012), shade (Galloway and Etterson, 2007), nutrient availability (Kou et al., 2011), salinity (Boyko et al., 2010), herbivory (Rasmann et al., 2012) or viral infection (Kathiria et al., 2010). As a result of all these studies, environmental maternal effects are now recognized as a relevant source of phenotypic variation that may have an essential role in local adaptations (Herman and Sultan, 2011; Holeski et al., 2012).

One of the most important transmission vehicles of maternal environmental effects is via seed provisioning (Herman and Sultan, 2011). Environmental conditions and resource availability may determine the amount of resources that the mother plants allocate to the developing seeds, which, in turn, may affect seed mass (SM), thus shaping many traits in seedling establishment and early growth, especially, under stressful and competitive conditions (Castro et al.,
2006; Metz et al., 2010). SM may be, thus, simply passively determined by the available resources in the maternal environment, where impoverished conditions lead to reduced SM, and thus, reduced seedling performance. However, maternal plants may also actively respond to environmental stress by maintaining or even increasing SM, in order to enhance the success rate of the inevitably reduced offspring number (Violle et al., 2009). In addition, responses of maternal plants to environmental conditions may affect not only mean SM but also SM variation within individual plants (Halpern, 2005; Violle et al., 2009). Producing seeds of different size may be advantageous, especially, in heterogeneous or unpredictable environments, where the optimal seed size varies through time and space (Halpern, 2005; Charpentier et al., 2012).

Maternal environmental effects can also be transmitted by other mechanisms that are not directly related to the amount of maternal resources allocated to seed provisioning, that is, SM-independent mechanisms. Recent studies have shown that different environmental factors may induce epigenetic changes in the mother trees that, transmitted through the seeds, can alter gene activity in the offspring modifying its phenotype (Boyko and Kovalchuk, 2011; Herman and Sultan, 2011). Transmission mechanisms of this SM-independent transgenerational plasticity include DNA methylation, histone modification and changes in small non-coding regulatory RNAs (Herman and Sultan, 2011). These epigenetic changes may persist over the whole life cycle, and there is even evidence that they could be 
transmitted across generations (Boyko et al., 2010). In contrast, when maternal influence is through the mediation of SM it tends to be more pronounced during the first stages of seedling development, becoming less significant as the seedling ages (Elwell et al., 2011).

Both SM-dependent and SM-independent maternal effects have interested quantitative geneticists, evolutionary biologists and more recently genomic researchers, as they are an uncontrolled source of phenotypic variation that could hamper the quantification of true genetic variation (Bischoff and Mueller-Schaerer, 2010; Elwell et al., 2011). Several methods have been used to account for this potential bias in quantitative genetic studies. Including SM as a covariate in the statistical analyses has been probably the most frequent (Hereford and Moriuchi, 2005; Hovenden et al., 2008; Cendán et al., 2012) but this method is generally insufficient to cover all maternal effects, as effects unrelated to seed provisioning remain unaccounted for (Cendán et al., 2012). Alternatively, maternal effects may be controlled by growing parental genotypes in a common environment for at least one generation before genetic testing (Bischoff and Mueller-Schaerer, 2010). However, this would be inoperative for long-lived species with delayed reproduction, such as conifers.

The vast majority of previous studies about transgenerational plasticity in plants have been focussed on annual plants, and very little information is available on the magnitude and ecological relevance of this source of phenotypic variation in long-lived trees (but see Yakovlev et al., 2010; Cendán et al., 2012). Conifers are, however, an interesting model for the study of maternal effects (Yakovlev et al., 2012). Conifer seeds contain a haploid endosperm of maternal origin that directly transmits both resource reserves and epigenetic marks from the mother to the offspring (Linkies et al., 2010). The long-lasting period of seed maturation in conifers (up to two years in the case of Maritime pine) also broadens the window period during which environmental cues can be imprinted into the seeds (Cendán et al., 2012). On the other hand, conifers have very large genome sizes with a large amount of non-coding DNA that could have a relevant role in the gene regulation processes (Yakovlev et al., 2012). However, not all the particularities of conifer trees favour the expression of maternal effects. Several particularities of their life history, such as the multiple reproductive cycles over their lifetime, or the larger year-to-year environmental heterogeneity within their prolonged lifespan, may largely alter the adaptive value and evolution of transgenerational plasticity in conifers.

The aim of this study was to identify the sources of variation of SM and offspring phenotype in a long-lived plant species, the Maritime pine (Pinus pinaster Aiton). Our main goal was to determine whether the maternal environment influences the early performance of the pine seedlings, and to disentangle at what extent these effects are mediated by seed provisioning. We studied SM and early offspring phenotype of seeds collected from 10 genotypes of $P$. pinaster clonally replicated in two contrasting environments, one with favourable conditions for the development of this pine species (in terms of growth and reproduction rate), and the other one with less favourable conditions (see Supplementary Table 1). Our experimental design allowed separating and quantifying the influence of the maternal genotype, the maternal environment and their interaction on both SM and early offspring phenotype. In particular, we were able to adequately separate and compare SM-dependent and -independent environmental maternal effects. Preliminary studies with the same plant material showed significant environmental maternal effects on both the percentage and the timing of germination in this pine species (Cendán et al., 2012). SM differences between maternal environments explained part, but not all, of the observed germination patterns.
Here, we performed a more comprehensive study to explore whether the maternal environment may also affect seedling performance, and the extent to which these effects are mediated by SM differences.

\section{MATERIALS AND METHODS}

\section{Plant material}

Maritime pine is a widespread forest tree in Southwest Europe and North Africa. Because of its rapid growth rate, this species is planted on a massive scale for timber production in Mediterranean climates all over the world, with seeds commonly collected from clonal seed orchards, that is, plantations designed for seed production in which several clonal copies (ramets) of a few selected genotypes are inter-crossed among each other. We took advantage of some of these genetically controlled plantations and collected seeds in two clonal seed orchards with exactly the same genetic material and spatial design but established in contrasting environmental conditions. The two seed orchards were established within the Galician Tree Breeding Program (Consellería do Medio Rural, Xunta de Galicia), and include 116 unrelated $P$. pinaster genotypes selected for their superior growth, stem form and branching habit in natural and planted stands within the Galician Coastal Population (NW Spain; see Zas et al. (2004) for details). Each selected genotype was clonally replicated by grafting scions on 2-year old seedlings. Within each seed orchard, 10 ramets of each genotype were established following a complete randomized design with 10 blocks and 1 ramet of each genotype per block. Thus, each seed orchard includes $116 \times 10=1160$ mother trees, and occupies around 3 ha. Environmental conditions strongly differ between the two seed orchards. The first (Sergude $42^{\circ} \mathrm{N}, 8.45^{\circ} \mathrm{W}$ ) is located in a site especially favourable for growing maritime pine, with mild temperatures, adequate moisture all year round and well drained, deep soils. The second (Monfero, $43.52^{\circ} \mathrm{N}, 7.93^{\circ} \mathrm{W}$ ) is located at the top of a hillside, with lower temperatures, exposure to strong winds and shallow soils (see Supplementary Table 1 for more details). Based on the large differences found in growth and reproduction rates between the two sites, we will refer to Sergude as the favourable maternal environment, and to Monfero as the stressful maternal environment.

\section{Cone and seed sampling, processing and sowing}

For the present study, we used 10 genotypes randomly selected among the 116 genotypes included in the seed orchards. In January 2009, we collected three to four mature cones from four to six ramets of each selected genotype within each maternal environment. Diameter at breast height was measured in all selected mother trees $(N=103)$. Cones were randomly selected within the crown of each sampled tree and collected using ladders and climbing tools. Damaged cones or cones in damaged branches were avoided. A total of 373 cones were sampled. Cones were opened by oven-drying at $35^{\circ} \mathrm{C}$, then weighed $( \pm 0.001 \mathrm{~g})$ and all seeds in each cone removed and stored at $4{ }^{\circ} \mathrm{C}$ in labelled polyethylene vials. The percentage of viable seeds in each cone was determined by decantation in cold water, where empty seeds remained floating at the surface (Cendán et al., 2012). The number of filled and empty seeds and total SM per cone were recorded after oven-drying the seeds a second time ( 7 days, $35^{\circ} \mathrm{C}$ ). A subsample of 24 filled seeds per cone was randomly selected, individually weighted $( \pm 0.0001 \mathrm{~g})$ and stored at $4^{\circ} \mathrm{C}$ until sowing. In October 2009, 8924 seeds of known individual weight were sown in vermiculite (0.5-2.0 mm coarse), using 96-well sowing trays with $9 \mathrm{~cm}$ tall wells. Trays were randomly disposed in a greenhouse with daily temperature fluctuating from 18 to $26^{\circ} \mathrm{C}$. Germination and ontogenic development were followed every 2-3 days as in Lazcano et al. (2010), and when the first set of true juvenile needles began to elongate, seedlings were harvested and shoot and root dry weight (7 days, $80^{\circ} \mathrm{C}$ ) were determined. Total dry weight (TDW) and root/shoot ratio (RSR) were derived from these values.

\section{Statistical analyses}

Sources of SM variation were characterized by calculating the mean, minimum and maximum, range of variation and coefficient of variation of SM at four levels: within cones $(N=373)$, within individual mother trees $(N=103)$, within genotypes $(N=10)$ and within maternal environments $(N=2)$.

For the analysis of cone weight, we used a general linear mixed model with the PROC-MIXED procedure of the SAS System (see results in Supplementary 
Table 2 and Supplementary Figure 1). We fitted a hierarchical model similar to those used to solve a split-plot design with two levels of nested experimental units (ramets and cones) in which measures from different cones within the same ramet (three to four sampled cones per ramet) were considered as repeated measures within the same subject (Littell et al., 2006). The effect of maternal environment (E; the two twin seed orchards) and the effect of block nested within each maternal environment $(\mathrm{B}(\mathrm{E}))$, which account for the effect of spatial variation within each seed orchard, were the fixed effects of the model. The maternal genotype $(G)$ and the interaction between maternal environment and maternal genotype $(\mathrm{G} \times \mathrm{E})$ were considered random factors. Micro-environmental variation at scales lower than the block size and other phenotypic effects associated to individual ramets, such as the effect of the rootstock, ontogeny or biotic interactions, was accounted for by including the effect of individual ramets $(\mathrm{G} \times \mathrm{B}(\mathrm{E}))$ as a random factor in the model. Diameter at breast height of each tree was also included as a fixed covariate in this model in order to account for possible allometric effects, but it was removed because it was not significant and did not improve the resolution of the model.

The effect of design factors on SM and seedling growth traits was also analysed with a general mixed model, but in this case the hierarchical model fitted was similar to those used to solve a split-split design with three levels of nested experimental units (ramet, cones and seeds; Littell et al., 2006), in which values within each experimental level were considered repeated measures within the same subject. That is, measures from different seeds within a cone and measures from different cones within a ramet were assumed to be dependent measures within cones and ramets, respectively. Besides the factors included in the model described above, the mixed model also included the random effect of cones within each ramet (cone $(G \times B \times E)$ ). Individual cone weight was included as a covariate in the analysis of SM, whereas covariation with germination time was considered in the analyses of seedling growth traits.

To discern the extent to which the effects of the maternal genotype and the maternal environment on seeding traits are mediated by seed-provisioning effects, we compare the results of the mixed models including and excluding the covariation of $S M$ and its interaction with the maternal genotype $(S M \times G)$ and the maternal environment $(\mathrm{SM} \times \mathrm{E})$. These last two terms account for the possible variation across genotypes and environments in the slopes of the covariation of seedling traits with SM.

We also analysed whether the maternal environment affects variation in SM within individuals rather than mean SM. To this end, we analysed the coefficient of variation in SM within each maternal tree using a conventional general mixed model with the fixed effects $\mathrm{E}$ and $\mathrm{B}(\mathrm{E})$, and the random effects $\mathrm{G}$ and $\mathrm{G} \times \mathrm{E}$. We used the coefficient of variation as the estimate of $\mathrm{SM}$ variation as it is less likely to be influenced as an artefact of variation in mean SM (Crean and Marshall, 2009).

The statistical significance of the variance components for each random factor in all statistical models was assessed using likelihood ratio tests, where the differences in two times the log-likelihood of the models including and excluding that random factor are distributed as one-tailed $\chi^{2}$, with one degree of freedom (Littell et al., 2006). To estimate the percentage of total variation explained by each factor, we repeated all analyses, considering all factors as random factors.

\section{RESULTS}

\section{Sources of variation of SM}

Maritime pine SM in the studied accessions was found to be extremely variable, ranging from 10 to $140 \mathrm{mg}$, with an overall mean of $66.7 \mathrm{mg}$ and a coefficient of variation of $31 \%$ (Table 1). Variability of SM was high both within individual trees and within cones, with some cones and some trees showing coefficients of variations higher than $20 \%$, and more than $60 \mathrm{mg}$ of differences between their lightest and heaviest seeds (Table 1). As well as the large within-individual variation, variation across individual trees was also very high, with mean SM spanning a sevenfold range of magnitude (from 15 to $116 \mathrm{mg}$, Table 1).
Table 1 Basic statistics of seed mass variation (overall variation) and range of variation (min-max) of seed mass basic statistics within cones, within ramets, within genotypes and within each maternal environment (stressful and favourable)

\begin{tabular}{|c|c|c|c|c|c|c|}
\hline & \multirow{2}{*}{$\begin{array}{c}\text { Overall } \\
\text { seed } \\
\text { mass }\end{array}$} & \multirow{2}{*}{$\begin{array}{l}\text { Within- } \\
\text { cone } \\
\text { range }\end{array}$} & \multirow{2}{*}{$\begin{array}{l}\text { Within- } \\
\text { ramet } \\
\text { range }\end{array}$} & \multirow{2}{*}{$\begin{array}{c}\text { Within- } \\
\text { genotype } \\
\text { range }\end{array}$} & \multicolumn{2}{|c|}{ Seed mass } \\
\hline & & & & & Stressful & Favourable \\
\hline$N$ & 8924 & 373 & 103 & 10 & 1 & 1 \\
\hline Mean (mg) & 66.7 & $\begin{array}{l}13.7- \\
128.8\end{array}$ & $\begin{array}{l}15.0- \\
116.5\end{array}$ & $\begin{array}{l}44.5- \\
89.3\end{array}$ & 53.2 & 79.1 \\
\hline Minimum (mg) & 10 & $\begin{array}{l}10- \\
117\end{array}$ & $10-86$ & $10-35$ & 10 & 31 \\
\hline Maximum (mg) & 140 & $\begin{array}{l}17- \\
140\end{array}$ & $21-140$ & $83-140$ & 103 & 140 \\
\hline Range (mg) & 130 & $7-61$ & $11-65$ & $67-105$ & 93 & 109 \\
\hline $\begin{array}{l}\text { Coefficient of var- } \\
\text { iation (\%) }\end{array}$ & 31.4 & $\begin{array}{l}4.4- \\
22.9\end{array}$ & $\begin{array}{l}6.8- \\
20.2\end{array}$ & $\begin{array}{c}20.2- \\
38.0\end{array}$ & 29.1 & 22 \\
\hline
\end{tabular}

Table 2 Sources of variation of mean seed mass for 10 genotypes clonally replicated in two contrasting maternal environments

\begin{tabular}{|c|c|c|c|c|}
\hline \multirow[t]{3}{*}{ Effect } & \multicolumn{4}{|c|}{ Seed mass } \\
\hline & DF or & & & Variance \\
\hline & VarComp & F or $\chi^{\mathrm{a}}$ & $\mathrm{P}$-value & components (\%) \\
\hline \multicolumn{5}{|l|}{ Fixed factors } \\
\hline Maternal environment (E) & 1,9 & 84.1 & $<0.001$ & 17.2 \\
\hline Block $(E)^{a}$ & 15,69 & 1.7 & 0.064 & 0.8 \\
\hline Cone weight ${ }^{b}$ & 1,8389 & 228.3 & $<0.001$ & 58.1 \\
\hline \multicolumn{5}{|l|}{ Random factors } \\
\hline Mother genotype (G) & $57.2 \pm 29.3$ & 13.0 & $<0.001$ & 8.9 \\
\hline $\mathrm{G} \times \mathrm{E}$ & $1.0 \pm 4.0$ & 0.1 & 0.376 & 0.0 \\
\hline Ramet $^{\mathrm{c}}$ & $28.5 \pm 6.0$ & 107.3 & $<0.001$ & 4.7 \\
\hline Cone (Ramet) ${ }^{\mathrm{a}}$ & $19.6 \pm 1.9$ & 1788.0 & $<0.001$ & 3.2 \\
\hline Residual & $43.7 \pm 0.7$ & & & 7.1 \\
\hline
\end{tabular}

Abbreviations: DF, degrees of freedom; VarComp, variance components.

$\mathrm{DF}$ and F-ratios are shown for fixed effects; VarComp \pm s.e. and associated $\gamma^{2}$ values showing their statistical significance are shown for random factors. Significant $(P<0.05) P$-values are typed in bold. The variance component (\%) column shows the percentage of total variation explained by each factor as obtained from a model in which all categorical factors are considered random ${ }^{b}$

${ }^{a}$ Block was nested within seed orchards, and cones were nested within ramets $(G \times B(E))$. ${ }^{\mathrm{b}}$ The percentage explained by the covariable (cone weight) was determined as the reduction of the total variance when including the covariate in the model.

${ }^{\mathrm{c}}$ Ramet $=\mathrm{G} \times \mathrm{B}(\mathrm{E})$.

SM significantly varied among genotypes and was highly influenced by the quality of the maternal environment (Table 2). Across genotypes, mean SM showed a twofold range of variation, ranging from 44.5 to $89.3 \mathrm{mg}$ (Table 1). Across environments, SM was nearly $50 \%$ greater in the favourable environment than in the stressful environment (Table 1). SM significantly covariated with the weight of the cones, which explained more than half of the variation of SM (Table 2). Cone weight was also highly variable among maternal environments and maternal genotypes, which together explained up to $70 \%$ of the total variation in cone weight (see Supplementary Table 2 and Supplementary Figure 1). Accordingly, the effect of both the maternal environment and the maternal genotype on the SM was much larger when the covariation with cone weight was not adjusted. 
The percentage of SM variation explained by these factors increased from $17.2 \%$ and $8.9 \%$, when accounting for cone weight covariation (Table 2), to $51 \%$ and $14 \%$, when excluding the covariable from the model, respectively. Accordingly, the reaction norms of the SM were clearer flatter and compressed when accounting for the covariation with cone weight (Figure 1). On the other hand, the lack of genotype by environment interaction (Table 2) indicates that the SM was significantly and similarly higher in the favourable maternal environment for all the 10 studied genotypes (Figure 1).

The maternal environment not only affected the mean SM, but also significantly modulated the within-individual variability in the SM $\left(\mathrm{F}_{1,9}=25.4, P<0.001\right.$; Supplementary Table 4$)$. Trees growing in the stressful maternal environment had a higher coefficient of variation in SM $(14.5 \pm 5.6 \%)$ than trees growing in the favourable environment $(10.8 \pm 0.5 \%)$. In contrast, the maternal genotype did not affect the variation in $\operatorname{SM}\left(\chi^{2}{ }_{1}=0.2 ; P=0.327\right)$, and neither there was interaction between the genotype and the maternal environments $\left(\chi^{2}{ }_{1}=0.8 ; P=0.186\right.$; Supplementary Table 4$)$.

\section{Sources of variation of offspring phenotype}

Without accounting for SM covariation, both the maternal environment and the maternal genotype significantly affected the total dry mass and the RSR of the resulting offspring (Table 3, left). A significant interaction was also observed in the case of seedling total dry mass. Seedlings coming from the favourable maternal environment were $35 \%$ larger than those coming from the stressful maternal environment and showed a larger RSR (Figure 2, triangles).

However, the variation among maternal genotypes became nonsignificant for both variables when the SM was considered as a covariate in the statistical models, whereas that of the maternal environment was strongly reduced for the TDW (Table 3, right; circles in Figure 2a). The covariation with SM was significant for the two seedling traits and especially strong in the case of the TDW. The significant $\mathrm{SM} \times \mathrm{E}$ and $\mathrm{SM} \times \mathrm{G}$ interactions (Table 3, right) also indicate that the slope of the covariation significantly differed among maternal environments and maternal genotypes. In the case of seedling TDW, the slope was significantly steeper for seeds coming from the stressful maternal environment $(6.38 \pm 0.30)$ than for seeds from the favourable maternal environment $\left(5.29 \pm 0.23 ; \mathrm{F}_{1,1958}=7.5\right.$,
$P=0.006$; Figure 3). When the statistical model accounted for all these covariation terms, the significant effect found for the maternal environment (Table 3, right) indicates that the intercept of these relationships also significantly differed between maternal environments (Figure 3).

The covariation of the RSR with the SM was weaker than for the total seedling dry weight and the slope of the covariation did not differ between maternal environments (no significant $\mathrm{SM} \times \mathrm{E}$ interaction; Table 3). The effect of the maternal environment not only remained highly significant when accounting for SM covariation (Table 3, right), but it was also even higher (around 10\% greater RSR in the favourable environment than in the stressful environment) than when SM covariation was not considered (5\% greater RSR in the favourable environment, Figure $2 \mathrm{~b}$ ).

\section{DISCUSSION}

\section{SM variation}

Because SM can considerably affect fitness (reviewed in Castro et al., 2006), classical life history theory predicts that it should be under strong stabilizing selection and show little variation within populations (Silvertown, 1989). However, many empirical observations do not fit with this prediction, and the range of variation in SM within populations is usually very high and even greater than that across populations (Susko and Lovett-Doust, 2000). Our results are consistent with those findings and indicate an extremely high variation (up to 14-fold) in SM both across and within individual trees (Table 1). Several non-exclusive explanations have been proposed to explain the maintenance of intrapopulation variation in SM. First, through modulating the resources that the maternal plant can allocate to the seeds, the maternal environment can be an important source of SM variation (Donohue, 2009). Our results indicate a strong effect of the maternal environment on SM with seeds coming from the favourable environment being around 50\% heavier than those coming from the stressful environment. This environmental effect was consistent for all the studied genotypes and explained more than half of the overall variation in SM. Our study also indicates considerable variation in SM across individuals of the same genotype within each environment, suggesting that microenvironmental variation and other phenotypic effects related to each single phenotype
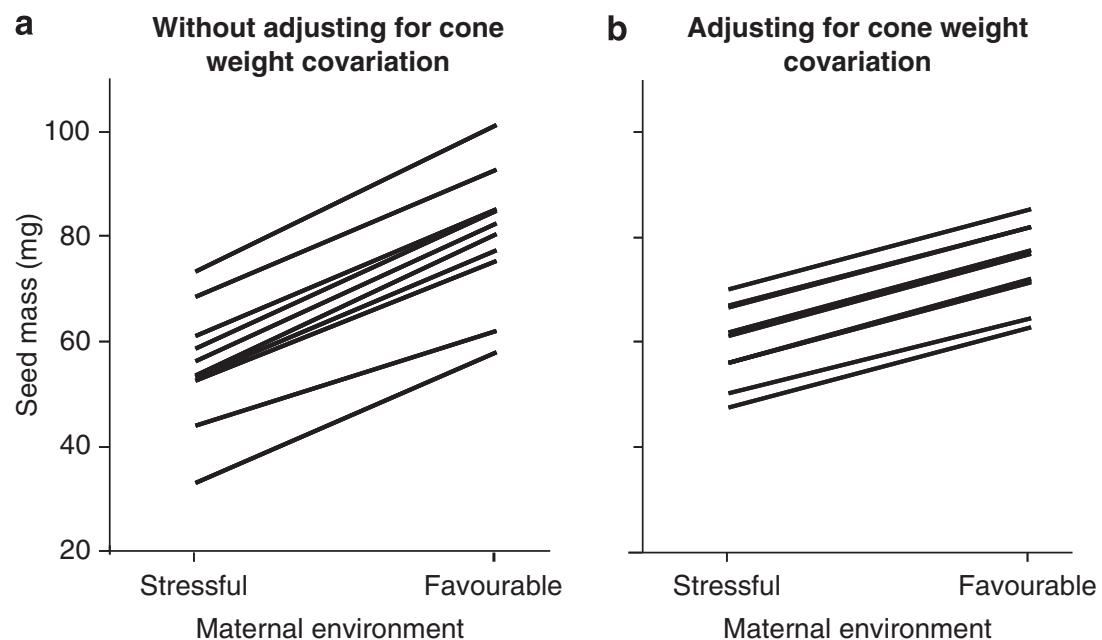

Figure 1 Reaction norms for the mean seed mass of 10 genotypes clonally replicated in two contrasting maternal environments. Best linear unbiased predictors as obtained from the corresponding mixed model (a) without considering the cone weight as a covariate and (b) adjusting for the covariation with the cone weight. 
Table 3 Results of the general mixed models for the analysis of seedling total dry weight (a) and seedling root/shoot ratio (b) without accounting for SM covariation (left) and accounting for SM covariation (right)

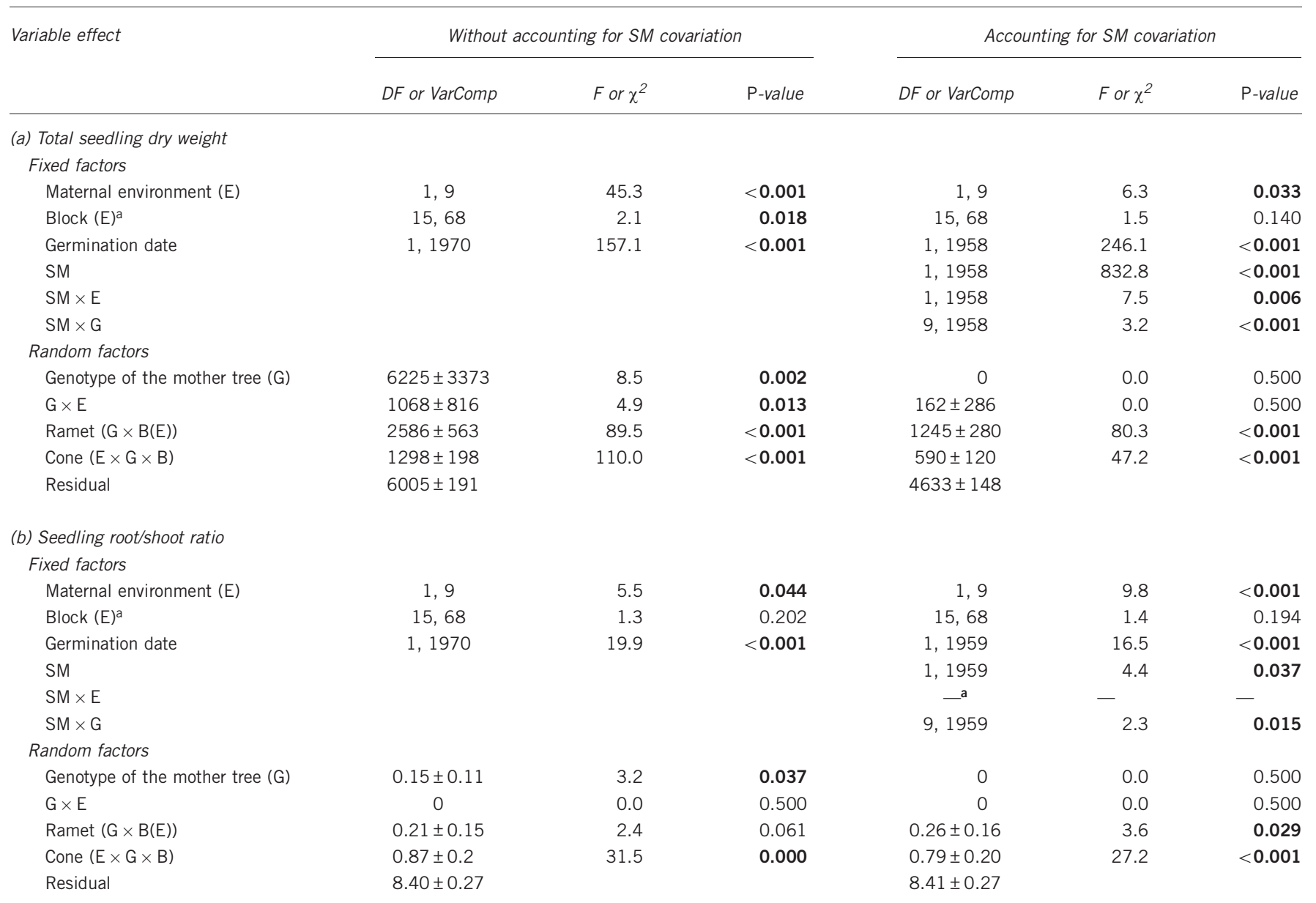

Abbreviations: DF, degrees of freedom; SM, seed mass; VarComp, variance components.

Degrees of freedom (DF) and F-ratios are shown for fixed effects; variance components (VarComp \pm s.e.) and associated $\chi^{2}$ values showing their statistical significance are shown for random factors. Significant $(P<0.05) P$-values are typed in bold.

aThe $\mathrm{SM} \times \mathrm{E}$ term was excluded from the model as it was not significant $\left(F_{1,1958}=0.0, P=0.982\right)$ and did not improve the resolution of the model.

such as ontogenetic development or biotic interactions may also be important sources of SM variation. In addition, allocation of resources to seeds can also vary among cones according to their position within the crown (Chanyenga et al., 2011). The observed large variation in SM among cones and the strong relationship between mean SM and cone weight $\left(r^{2}=0.76, P<0.001, N=373\right)$ may be reflecting these positional effects. However, environmental and genotypic effects on SM remained highly significant when accounting for covariation with cone weight, indicating that the maternal environment and the maternal genotype control the variation in SM irrespective of the amount of resources allocated to the cone. Taking all these results together, we can conclude that SM in this pine species is strongly determined by the environmental conditions where the mother tree grows, and this may have important consequences for offspring development (see discussion below). In addition, the observed genetic variation in SM may allow the evolution of this life history trait according to environmental conditions, providing that it affects offspring seedling performance, that the effect differs among maternal environments and that a significant part of the genetic variation is heritable. Further research analysing parent-offspring regression and/or family trials should determine the amount of additive variation within the observed genetic variation in SM in this pine species. Because SM has a relevant role in many important life history processes, many studies have focussed on determining the sources of SM variation in different plant species, but the effects of the maternal environment and the maternal genotype have not always been adequately separated (Blodner et al., 2007; Guo et al., 2010), and when they have been separated (Halpern, 2005; Galloway et al., 2009; House et al., 2010), they have usually referred to annual plants (but see Stoehr et al., 1998). Results are very variable. Some authors only found effects of the maternal environment (for example, Galloway et al., 2009), whereas others have found the opposite (for example, Halpern, 2005). Most frequently, however, both factors have been found to significantly affect mean SM (for example, Stoehr et al., 1998; Elwell et al., 2011). Our results agree with these studies, and clearly show a strong genetic component in SM as well as a large influence of the maternal environment (Table 2, Figure 1). Interestingly, the lack of a significant $\mathrm{G} \times \mathrm{E}$ interaction indicated that the effect of the maternal environment was similar for all the studied genotypes. However, the lack of genetic variation in plasticity should be interpreted with care as the studied genotypes were selected by the same criteria and shared a common phenotype. 

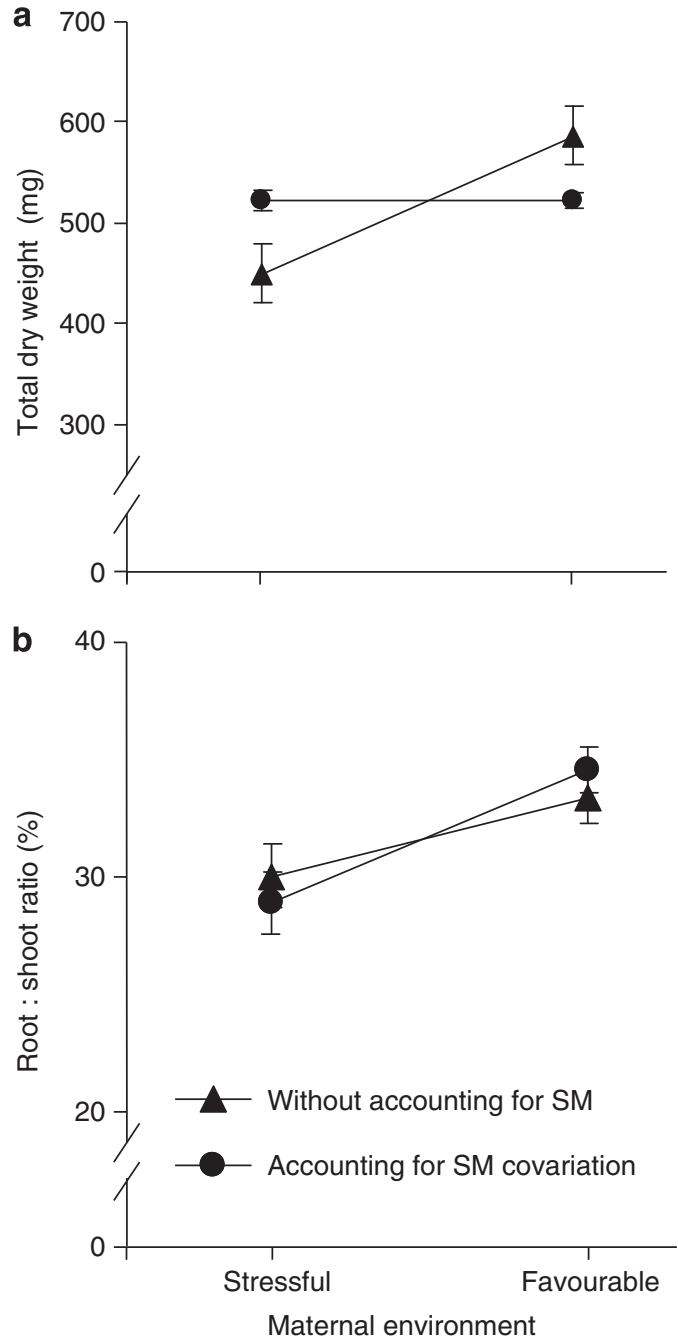

Figure 2 Total dry weight (a) and root/shoot ratio (b) of the offspring of 10 genotypes clonally replicated in two contrasted environments. Least square means ( \pm s.e.) obtained from the mixed models including (circles) and excluding (triangles) the seed mass (SM) as a covariate are presented.

These genotypes do not represent, therefore, all the potential variation within the studied population.

\section{Maternal environmental effects on SM variability}

Our results indicate that the maternal environment not only affected the mean SM but also it significantly modulated the variability of SM within individual trees, with larger variation in trees growing in the stressful environment. These results are consistent with previous findings in which reduced resource availability has been associated with increased within-individual variability in SM (Halpern, 2005). Increased variability in SM may enhance the likelihood of establishing in a wider range of environmental conditions, and it has been proposed that this is an adaptive strategy that may increase mother fitness in heterogeneous or unpredictable environments (Crean and Marshall, 2009; Charpentier et al., 2012). The opposite has also been reported, however. Under conditions of limited resources, mother plants may benefit from prioritizing a single optimum seed size that maximizes the success of the seedlings under the stressful conditions where they will establish (Violle et al., 2009). In both cases variability

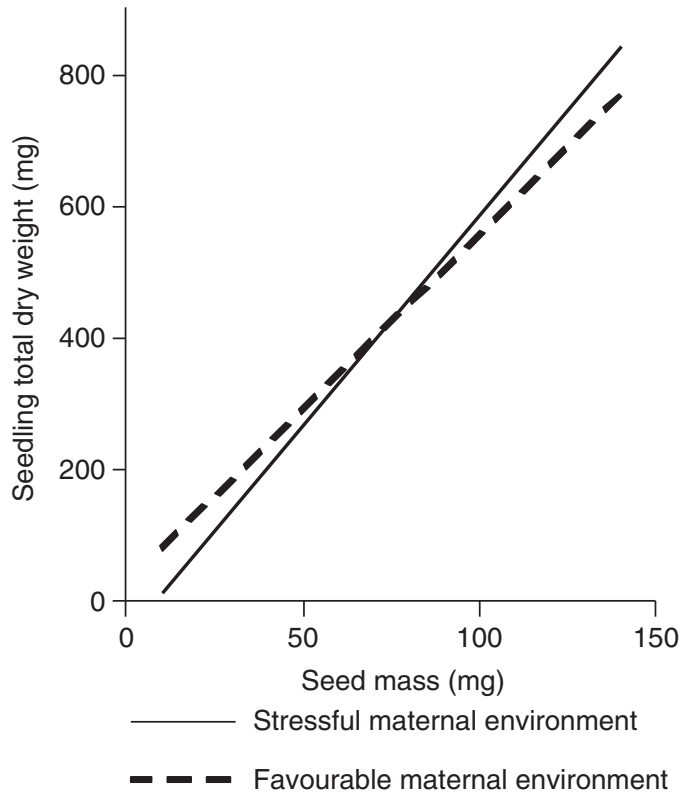

Figure 3 Linear relationship between the seed mass and the seedling total dry weight for the two maternal environments as obtained from a heterogenous slope covariation mixed model. The slopes significantly differ, with a steeper relationship for seeds coming from the stressful maternal environment, and the intercept also significantly differed between maternal environments.

in SM could be interpreted as a parental trait per se that may respond to selection according to the environmental conditions (Moles and Westoby, 2006). In this sense, the lack of genetic variation in SM variability observed here would imply a potential constraint on the evolution of this trait. SM variability therefore seems to be a plastic trait controlled by environmental conditions alone, in accordance with results found by other studies in annual plants (Castellanos et al., 2008).

Variability in SM may also arise due to other causes with no adaptive significance (Halpern, 2005; Castellanos et al., 2008). Under stressful environmental conditions, developmental instability may limit the ability to equally provision all seeds due to constraints in resource allocation to seeds (Castellanos et al., 2008). Our results do not indicate whether the observed differences in SM variability are merely a passive response to the environment or it is under other kind of control by the mother trees; to draw conclusions about it adaptive value would require analysis of the fitness consequences of SM variability for the mother trees.

Maternal environment and SM effects on seedling performance Our results indicated a strong effect of the maternal environment on offspring performance. Without accounting for SM covariation, seedlings derived from seeds from the favourable maternal environment showed both higher aboveground and belowground biomass. These results agree with other studies reporting larger offspring phenotypes of seeds coming from favourable maternal environments (Leishman et al., 2000; Castro et al., 2006). However, whether this maternal environmental effect is merely an indirect consequence of SM differences between environments or whether it may be an active transgenerational response mediated by other epigenetic mechanisms remains an unresolved question (Hereford and Moriuchi, 2005; Boyko and Kovalchuk, 2011; Cendán et al., 2012). Our data show 
that, when the covariation with SM is properly accounted for in the statistical model, the effect of the maternal environment on offspring biomass, although still significant, was strongly reduced (see Table 3). This result suggests that most of the transgenerational maternal effects on seedling size were mediated by effects related to seed provisioning. The observed differences in seedling total dry mass between maternal environments were, thus, derived principally from the large differences in SM between environments. However, our results also indicated that the influence of SM on seedling biomass differed between the seeds collected in the two maternal environments, with a strong and steeper seed-to-seedling biomass relationship for seeds from the stressful environment (Figure 3). That the benefits of heavier seeds are higher under stressful conditions have been demonstrated for different plant species (Metz et al., 2010), but the key finding of our analyses is that the seed-to-seedling relationship was determined by the maternal environment rather than by the environmental conditions where the seeds are grown, which, in our study, were similar for all seedlings. Two non-exclusive mechanisms may explain these results. First, because of the large environmental differences between the two maternal sites, the quality of the resources allocated to the seeds may strongly differ between them (Violle et al., 2009). Bigger seeds from the two environments may, thus, differ in their chemical reserve composition, and this seed quality may impact seedling performance. However, the fact that the relationship between SM and seedling biomass was steeper for the resources-deprived maternal environment reduces the likelihood of this argument Alternatively, even though seed provisioning could determine most of the quantitative phenotypic changes, epigenetic mechanisms regulated by the environmental conditions of the maternal plants and differentially expressed depending on the SM may also occur (that is, interactive effects between seed provisioning and epigenetic transgenerational programming). Those SM-dependent epigenetic mechanisms, that is, a mixture of heritable and non-heritable maternal effects (sensu Boyko and Kovalchuk, 2011), are feasible whenever epigenetic regulation is resource dependent. Other authors have also found a significant $\mathrm{SM} \times$ maternal environment interaction on seedling growth, but they did not study the responsible mechanisms (Hovenden et al., 2008). Nevertheless, irrespective of the involved mechanisms, our results suggest that the maternal environment, rather than directly affecting the seedling total dry mass, modulates the extent to which the seedling phenotype depends on the $\mathrm{SM}$, that is, a regulatory maternal effect.

The maternal environment not only affected total seedling dry mass, but also modulated the allocation of biomass to shoots and roots, with seedlings from the stressful maternal environment prioritizing relative biomass allocation to aerial parts. However, in contrast with what occurred with total seedling biomass, this effect was not related to differences in seed provisioning. In accordance with previous studies (Hovenden et al., 2008), when considering the whole data set, we found that SM was negatively correlated with seedling RSR, with the smaller seeds leading to seedlings with greater RSR. However, when considering the effect of the maternal environment, we found that the stressful environment strongly determined a lower seedling RSR, even when the SM in that environment was the smaller. In consequence, the effect of the maternal environment on seedling biomass allocation was even more pronounced when the statistical model properly accounted for the SM covariation (Figure 2b). Thus, as reported for germination traits in this pine species (Cendán et al., 2012), the effect of the maternal environment on seedling biomass allocation appeared to be mediated by SM-independent mechanisms.
Previous studies have also shown that the maternal abiotic environment can modulate seedling biomass allocation (Hovenden et al., 2008; Sultan et al., 2009). Warmer maternal environments have been found to produce offspring with greater RSR in a grass species (Hovenden et al., 2008). The two maternal environments of the present study not only differed, however, in the temperature regime but also had extremely different edaphic properties (Cendán et al., 2012), with the warmer environment also having the best quality soils. According to this, one could expect that seedlings coming from the stressful environment would benefit from prioritizing allocation to roots rather than to shoots in order to favour the uptake of the limited edaphic resources of this environment (Moles and Westoby, 2006; Sultan et al., 2009), whereas those coming from the favourable environment would benefit from prioritizing the growth of the aerial part in order to increase competitive ability for light (Galloway and Etterson, 2007). The observed results, however, point in the opposite direction. Different species, even closely related congeners, are known to show different transgenerational plasticity in response to a particular maternal environment stress, and these plastic responses do not always show an adaptive value (Sultan et al., 2009). Further studies, controlling the environmental factors responsible of the maternal stress and using reciprocal cross transplanting experiments, are needed to explore the adaptive value of these transgenerational responses in this pine species.

\section{DATA ARCHIVING}

Data deposited in the Dryad repository: doi:10.5061/dryad.k7clm.

\section{CONFLICT OF INTEREST}

The authors declare no conflict of interest.

\section{ACKNOWLEDGEMENTS}

This work was supported by the Spanish Plan Nacional de I + D + I (INIA-RTA2007-100, PSE310000 and AGL2010-18724) and co-financed by EU-FEDER. L.S. was supported by a DOC-INIA grant at the Centro de Investigación Forestal de Lourizán. We thank Xunta de Galicia for allowing us to work in the seed orchards. The two seed orchards were established by the Centro de Investigación Forestal de Lourizán, Xunta de Galicia. We thank Benito Santos, Raúl de la Mata, Patricia Martíns, Montse Peso, Oscar Vilariño, Brétema Dorado, Fernando González, Rocío Huelga, Peregrina Méndez, Mercedes Vázquez for their help in field and greenhouse sampling. Avelina González, Rocio Campanó and Luz Pato are also acknowledged for their help in SM determinations and germination surveys. We also thank David Brown for language edition and two anonymous reviewers for their suggestions to improve the manuscript.

Bischoff A, Mueller-Schaerer H (2010). Testing population differentiation in plan species-how important are environmental maternal effects. Oikos 119: 445-454.

Blodner C, Goebel C, Feussner I, Gatz C, Polle A (2007). Warm and cold parenta reproductive environments affect seed properties, fitness, and cold responsiveness in Arabidopsis thaliana progenies. Plant Cell Environ 30: 165-175.

Boyko A, Blevins T, Yao Y, Golubov A, Bilichak A, Ilnytskyy Y et al. (2010). Transgenerational adaptation of arabidopsis to stress requires DNA methylation and the function of Dicer-Like proteins. PLoS One 5: e9514.

Boyko A, Kovalchuk I (2011). Genome instability and epigenetic modification-heritable responses to environmental stress? Curr Opin Plant Biol 14: 260-266.

Castellanos MC, Medrano M, Herrera CM (2008). Subindividual variation and genetic versus environmental effects on seed traits in a European Aquilegia. Botany 86 $1125-1132$

Castro J, Hódar JA, Gómez JM (2006). Seed size. In: Basra AS (eds) Handbook of Seed Science and Technology. Haworth Press: New York, pp 397-428.

Cendán C, Sampedro L, Zas R (2012). The maternal environment determines the timing of germination in Pinus pinaster. Environ Exp Bot; doi:10.1016/j.envexpbot.2011.11.022 
Crean AJ, Marshall DJ (2009). Coping with environmental uncertainty: dynamic bet hedging as a maternal effect. Phil Trans R Soc B 364: 1087-1096.

Chanyenga TF, Geldenhuys CJ, Sileshi GW (2011). Effect of population size, tree diameter and crown position on viable seed output per cone of the tropical conifer Widdringtonia whytei in Malawi. J Tropical Ecol 27: 515-520.

Charpentier A, Anand M, Bauch CT (2012). Variable offspring size as an adaptation to environmental heterogeneity in a clonal plant species: integrating experimental and modelling approaches. J Ecol 100: 184-195.

Donohue K (2009). Completing the cycle: maternal effects as the missing link in plant life histories. Phil Trans R Soc B 364: 1059-1074.

Elwell AL, Gronwall DS, Miller ND, Spalding EP, Brooks TLD (2011). Separating parental environment from seed size effects on next generation growth and development in Arabidopsis. Plant Cell Environ 34: 291-301.

Galloway LF, Etterson JR (2007). Transgenerational plasticity is adaptive in the wild Science 318: 1134-1136.

Galloway LF, Etterson JR, McGlothlin JW (2009). Contribution of direct and maternal genetic effects to life-history evolution. New Phytol 183: 826-838.

Guo H, Mazer SJ, Du G (2010). Geographic variation in seed mass within and among nine species of Pedicularis (Orobanchaceae): effects of elevation, plant size and seed number per fruit. J Ecol 98: 1232-1242.

Halpern SL (2005). Sources and consequences of seed size variation in Lupinus perennis (Fabaceae): adaptive and non-adaptive hypotheses. Am J Bot 92: 205-213.

Hereford J, Moriuchi KS (2005). Variation among populations of Diodia teres (Rubiaceae) in environmental maternal effects. J Evol Biol 18: 124-131.

Herman JJ, Sultan SE (2011). Adaptive transgenerational plasticity in plants: case studies, mechanisms, and implications for natural populations. Front Plant Sci 2: $1-10$.

Herman JJ, Sultan SE, Horgan-Kobelski T, Riggs C (2012). Adaptive transgenerational plasticity in an annual plant: grandparental and parental drought stress enhance performance of seedlings in dry soil. Integr Comp Biol 52: 77-88.

Holeski LM, Jander G, Agrawal AA (2012). Transgenerational defense induction and epigenetic inheritance in plants. Trends Ecol Evol 27: 618-626.

House C, Roth C, Hunt J, Kover PX (2010). Paternal effects in Arabidopsis indicate that offspring can influence their own size. Phil Trans R Soc B 277: 2885-2893.

Hovenden MJ, Wills KE, Chaplin RE, Schoor JKV, Williams AL, Osanai Y et al. (2008). Warming and elevated $\mathrm{CO}(2)$ affect the relationship between seed mass, germinability and seedling growth in Austrodanthonia caespitosa, a dominant Australian grass. Global Change Biol 14: 1633-1641.

Kathiria P, Sidler C, Golubov A, Kalischuk M, Kawchuk LM, Kovalchuk I (2010). Tobacco mosaic virus infection results in an increase in recombination frequency and resistance to viral, bacterial, and fungal pathogens in the progeny of infected tobacco plants. Plant Physiol 153: 1859-1870.

Kou HP, Li Y, Song XX, Ou XF, Xing SC, Ma J et al. (2011). Heritable alteration in DNA methylation induced by nitrogen-deficiency stress accompanies enhaced tolerance by progenies to the stress in rice (Oryza sativa). J Plant Physiol 168: 1685-1693.

Lazcano C, Sampedro L, Zas R, Domínguez J (2010). Vermicompost enhances germination of the maritime pine (Pinus pinaster Ait). New For 39: 387-400.

Leishman MR, Wright IJ, Moles AT, Westoby M (2000). The evolutionary ecology of seed size. In: Fenner M (eds) Seeds: the Ecology of Regeneration in plant Communities. CABI: Wallingford, pp 31-57.

Linkies A, Graeber K, Knight C, Leubner-Metzger G (2010). The evolution of seeds. New Phytol 186: 817-831.

Littell RC, Milliken GA, Stroup WW, Wolfinger RD, Schabenberger O (2006). SAS System for Mixed Models, 2nd edn. SAS Institute: Cary, NC.

Metz J, Liancourt P, Kigel J, Harel D, Sternberg M, Tielboerger K (2010). Plant survival in relation to seed size along environmental gradients: a long-term study from semi-arid and Mediterranean annual plant communities. J Ecol 98: 697-704.

Moles AT, Westoby M (2006). Seed size and plant strategy across the whole life cycle. Oikos 113: 91-105.

Rasmann S, Vos MD, Casteel CL, Tian D, Halitschke R, Sun JY et al. (2012). Herbivory in the previous generation primes plants for enhanced insect resistance. Plant Physiol 158: $854-863$

Silvertown J (1989). The paradox of seed size and adaptation. Trends Ecol Evol 4: 24-26.

Stoehr MU, L'Hirondelle SJ, Binder WD, Webber JE (1998). Parental environment aftereffects on germination, growth, and adaptive traits in selected white spruce families. Can J For Res 28: 418-426.

Sultan SE, Barton K, Wilczek AM (2009). Contrasting patterns of transgenerational plasticity in ecologically distinct congeners. Ecology 90: 1831-1839.

Susko DJ, Lovett-Doust L (2000). Patterns of seed mass variation and their effects on seedling traits in Alliaria petiolata (Brassicaceae). Am J Bot 87: 56-66.

Violle C, Castro H, Richarte J, Navas ML (2009). Intraespecific seed trait variations and competition: passive or adaptive response? Func Ecol 23: 612-620.

Yakovlev I, Fossdal CG, Skrøppa T, Olsen JE, Jahren AH, Johnsen $\emptyset$ (2012). An adaptive epigenetic memory in conifers with important implications for seed production. Seed Sci Res 22: 63-76.

Yakovlev IA, Fossdal CG, Johnsen O (2010). MicroRNAs, the epigenetic memory and climatic adaptation in Norway spruce. New Phytol 187: 1154-1169.

Zas R, Merlo E, Fernández-López J (2004). Genotype x environment interaction in Maritime pine families in Galicia, Northwest Spain. Silvae Genet 53: 175-182.

Supplementary Information accompanies this paper on Heredity website (http://www.nature.com/hdy) 